
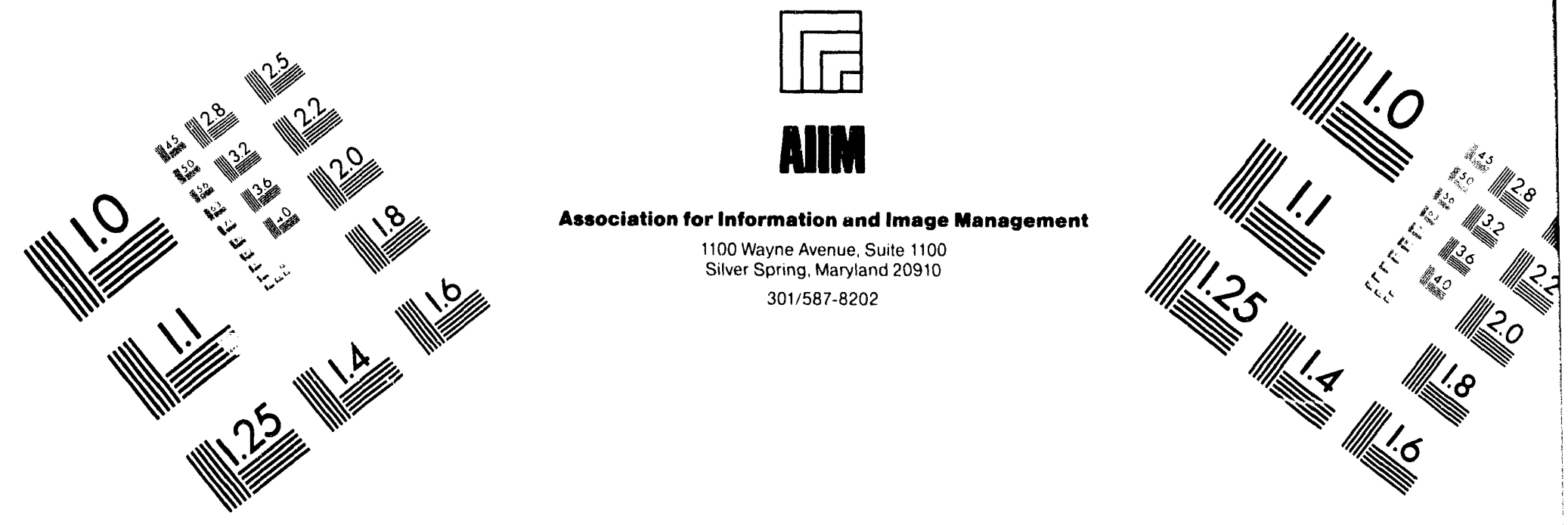

\title{
Centimeter
}

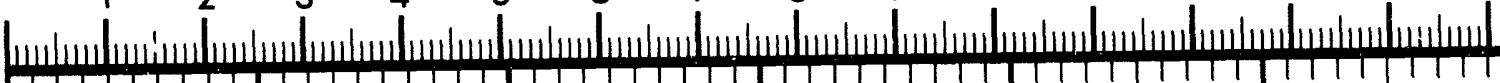

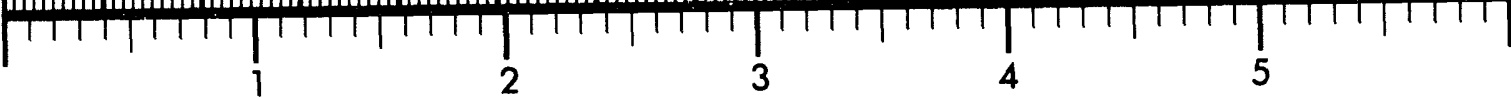
Inches
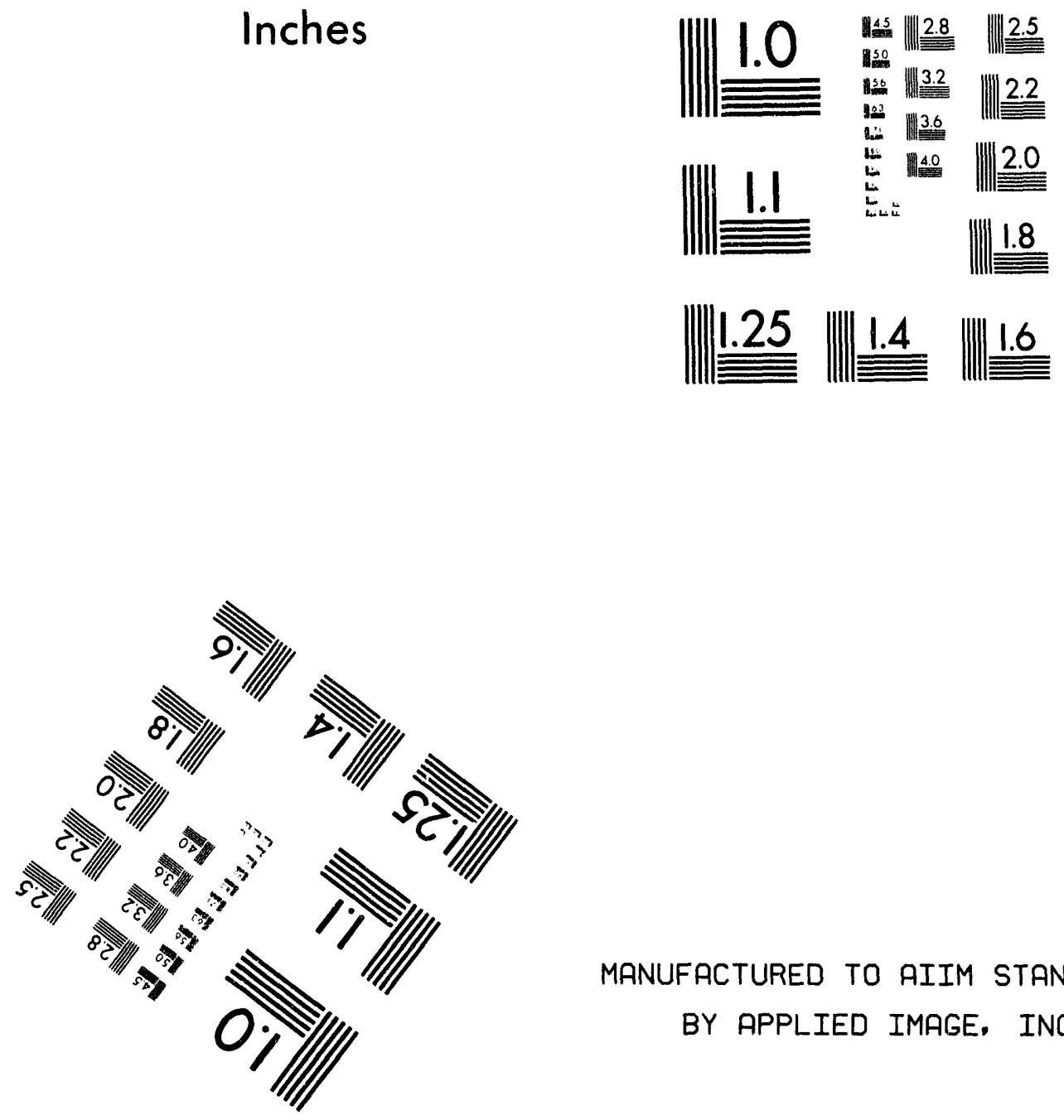

MANUFACTURED TO AIIM STANDARDS BY APPLIED IMAGE, INC.

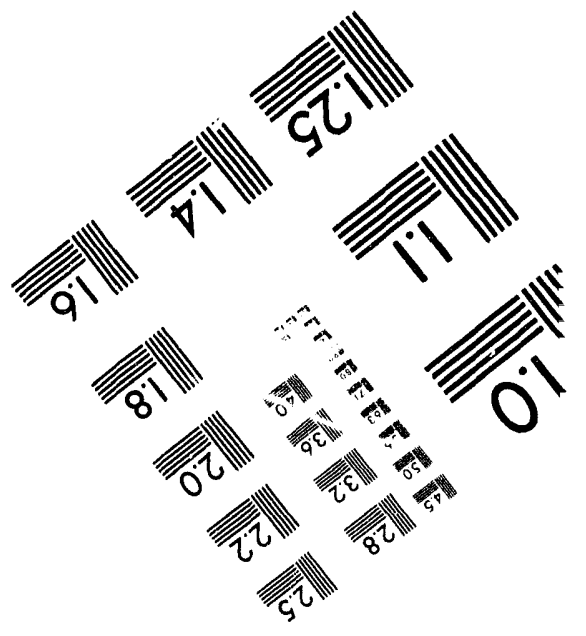



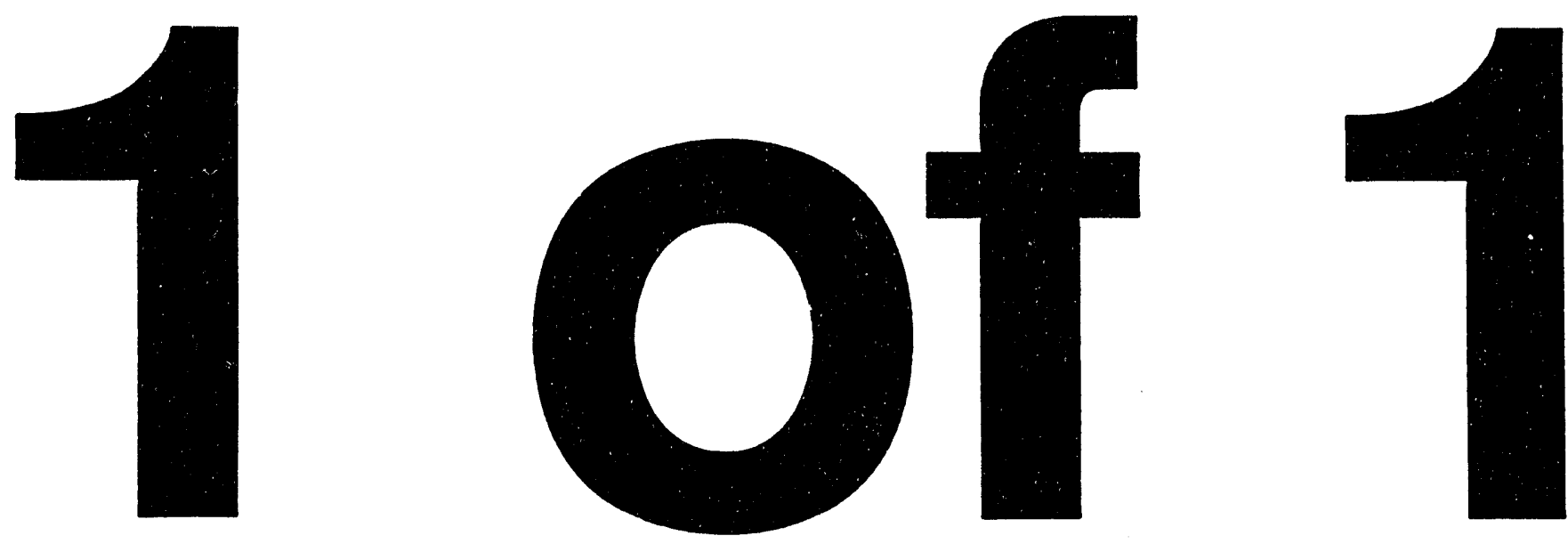


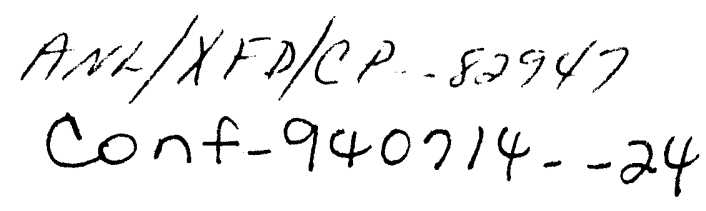

\title{
Modular Filter Design for the White-Beam Undulator/Wiggler Beamlines at the Advanced Photon Source
}

\author{
C. Brite, D. Shu, T. Nian, Z. Wang, D. Haeffner, E. Alp, and T. Kuzay \\ Experimental Facilities Division \\ Argonne National Laboratory \\ Advanced Photon Source \\ Argonne, IL 60439
}

\begin{abstract}
A new filter has been designed at Argonne National Laboratory that is intended for the use in undulator/wiggler beamlines at the Advanced Photon Source. The water-cooled frame allows up to four individual filter foil banks simultaneously in the beam path. Additionally, the bottom of each frame holds two thin $(20 \mu \mathrm{m})$ uncooled carbon filters in tandem for low-energy filtering. Therefore, a maximum of 625 filter selection combinations is theoretically possible. The design is intelligent, compact and modular, with great flexibility for the users. To prevent accidental movement of the filter, effort has been taken to provide a mechanically locked, fail-safe actuator system. Programming aspects are under development as part of our general personnel and equipment protection system.
\end{abstract}

Aspects of the design and operational principles of the filter are presented in this paper.

\section{Conceptual Design}

The effective use of filters in a general experimental beamline requires a large variety of different filters to cover the entire beam spectrum. The filter assembly described is designed to provide filtering with cutoffs up to $30 \mathrm{keV}$ and above. To provide additional flexibility to the experimenters, a modular design was required. This allows the option of adding or exchanging individual filters with minimum effort. In addition, this assembly can be build as a double filter bank assembly or a quadruple filter bank assembly, depending on the needs of the individual beamline. The design had to be UHV compatible. Water cooling was required for each filter foil (Fig.1 and Fig.2). Finally, the requirements called for individual motor controlled actuators for each filter bank. These actuators are to be linked to the APS equipment protection system.

\section{Parameters}

Table 1. Parameters [1] of APS Wiggler A [2] and Undulator A [3] for the Beamline Filter Design

\begin{tabular}{|l|l|l|}
\hline & Wiggler $\mathrm{A}$ & Undulator A \\
\hline Max. deflection parameter, $\mathrm{K}$ & 7.9 & 2.23 \\
\hline $\mathrm{K} \gamma[\mu \mathrm{rad}]$ & 577 & 163 \\
\hline Total power $[\mathrm{kW}]$ & 7.4 & 3.8 \\
\hline Peak power $\left[\mathrm{kW} / \mathrm{mrad}^{2}\right]$ & 73 & 134 \\
\hline Filter to source distance $[\mathrm{m}]$ & 26 & 26 \\
\hline
\end{tabular}




\section{Material}

Graphite was chosen as the main filter material because its power absorption is low, and it has a high melting point. The selection of its mechanical thickness is based on anticipated experimental requirements and the availability and cost of graphite.

Table 2. Parameters [4] of the graphite foils

\begin{tabular}{|l|l|l|l|}
\hline & $\begin{array}{l}\text { Pyrolitic graphite } \\
\mathrm{t}=150 \mu \mathrm{m} \text { to } 2000 \mu \mathrm{m}\end{array}$ & $\begin{array}{l}\text { Isotropic graphite } \\
\mathrm{t}=56 \mu \mathrm{m}\end{array}$ & $\begin{array}{l}\text { Isotropic graphite } \\
\mathrm{t}=20 \mu \mathrm{m} \text { to } 25 \mu \mathrm{m}\end{array}$ \\
\hline Density at $25^{\circ} \mathrm{C}(\mathrm{g} / \mathrm{cc})$ & 2.1 & 2.1 & 0.9 \\
\hline $\begin{array}{l}\text { Thermal conductivity } \\
25^{\circ} \mathrm{C}(\mathrm{a}+\mathrm{b} \text { plane) }\end{array}$ & 340 watts $/ \mathrm{m}{ }^{\circ} \mathrm{K}$ & N/A & N/A \\
\hline $\begin{array}{l}\text { Thermal conductivity } \\
25^{\circ} \mathrm{C}(\mathrm{c} \text { plane) }\end{array}$ & 2 watts $/ \mathrm{m}{ }^{\circ} \mathrm{K}$ & N/A & N/A \\
\hline Grain size $(\mu \mathrm{m})$ & Under $\mathrm{R} \& \mathrm{D}$ & $1-2$ & $1-2$ \\
\hline
\end{tabular}

Table 3. Graphite foil arrangement

\begin{tabular}{|l|l|l|l|}
\hline Filter Bank 1 & Filter Bank 2 & Filter Bank 3 & Filter Bank 4 \\
\hline Blank & Blank & Blank & Blank \\
\hline $300 \mu \mathrm{m} \mathrm{C}$ & $700 \mu \mathrm{m} \mathrm{C}$ & $2000 \mu \mathrm{m} \mathrm{C}$ & R \& D \\
\hline $300 \mu \mathrm{m} \mathrm{C}$ & $500 \mu \mathrm{m} \mathrm{C}$ & $1000 \mu \mathrm{m} \mathrm{C}$ & R \& D \\
\hline $20 \mu \mathrm{m} \mathrm{C}^{*}$ & $56 \mu \mathrm{m} \mathrm{C}$ & $150 \mu \mathrm{m} \mathrm{C}$ & R \& D \\
\hline $2 \times 20 \mu \mathrm{m} \mathrm{C}^{*}$ & $2 \times 20 \mu \mathrm{m} \mathrm{C} \mathrm{C}^{*}$ & $2 \times 20 \mu \mathrm{m} \mathrm{C}$ & $2 \times 20 \mu \mathrm{m} \mathrm{C}$ \\
\hline
\end{tabular}

* The density $(0.9$ to $1.2 \mathrm{~g} / \mathrm{cc})$ is approximately $50 \%$ less than the bulk density of graphite $(1.8 \mathrm{~g} / \mathrm{cc})$.

The arrangement of the graphite foils is based on our filter absorption calculations. In all cases, the maximum absorbed power does not exceed 850 watts for any wiggler filter foil or 400 watts for any undulator filter foil. After determining the maximum permissible temperature ( $2000^{\circ} \mathrm{C}$ for graphite) on each individual filter foil, the limits of total power ( 960 watts) absorbed by each filter were set. With this in mind, the arrangement of filter foils becomes evident. The first graphite filter to intersect the photon beam may not be thicker than $300 \mu \mathrm{m}$ (Fig.1). The second consecutive graphite foil in the beam path may not be thicker than $1000 \mu \mathrm{m}$. Any filter thereafter could be up to 5 -mm-thick graphite, but with design limitations the maximum mechanical thickness of any filter foil should not exceed $2.5 \mathrm{~mm}$. To provide for the beam to pass through the assembly unfiltered, each filter bank is left with one open position (blank).

\section{Filter}

A complete set of filters (Fig.3) for an insertion device (ID) beamline at the APS consists of four filter banks, four actuators, two individual UHV compatible housings, two bellows, and one vacuum pump. A set of bellows separate the housings from each other and adjacent components. Each housing contains two water-cooled filter banks made of copper. An individual filter bank (Fig.4) consists of five beam apertures with the upper four water-cooled positions providing mounting space for one filter foil each. The bottom aperture provides mounting space for two thin $(20-24 \mu \mathrm{m})$ filter foils, which will be cooled by radiation scatter only. Each filter bank is mounted to an individual actuator. This allows up to four water-cooled or a maximum of eight uncooled filter foils in the beam path simultaneously.

The attachment of the filter foils utilizes a clamping mechanism (Fig.5). It is designed to reduce the very high localized thermal stresses (Fig.6 and 7) by allowing the foils to expand during a temperature 
rise while providing enough clamping force to assure good thermal contact between the foils and the cooling frame. Additionally, the foil mounting surface of the copper filter banks has been gold plated to reduce oxidation, thus providing a smoother gliding surface. For optimal heat transfer, the water-cooled foils are clamped on the top and bottom of each piece. The thin uncooled foils are clamped on the top side only, with the bottom part trapped in a gap allowing free expansion.

To absorb scatter radiation and prevent temperature rise in the housings, water-cooled copper shields have been installed between the filter banks and each housing. Each shield is equipped with a small entrance and exit aperture to provide unrestricted beam passage.

\section{Actuator}

Each filter bank actuator (Fig.8) operates independently utilizing a single, vertical rail assembly, a worm gear jack, and a stepping motor. A set of precision switches provides the positioning indication. At any of the five possible positions of each filter bank, two switches must be contacted. This adds redundancy to the system. To prevent accidental movement, a mechanical lock has been developed. Each switch plunger is buried inside a small recess. The pins to actuate these plungers are mounted to a solenoid. The solenoid, in its deenergized state, pushes the pins inside the recess in contact with the switch plunger. To change filter foils in the assembly, the solenoid must be activated. This retrieves the pins from the hard lock, and the actuator can be moved. Once arrived at the new location, the solenoid deactivates, and the pins again activate two switches inside the recess. In case of loss of motor-step counts, a set of precision home switches were added. In addition, these switches in combination with hard stops should prevent the actuator from running past its boundaries.

\section{Controls}

The development of an intelligent controls system is currently underway. It is being incorporated into the equipment protection system (EPS). To change the setting for the filter combination, the experimenter issues a request to the operator interface (OI), which then sends a signal to the EPS. The EPS closes the photon shutter. The system then compares the requested filter combination with present beam current, undulator gap and selection with a prewritten software lookup table. If the request is determined to be safe, the EPS opens the mechanical locks and the actuators move to their new position. Only after the position indication switches on the actuators have been read, can the EPS open the photons shutters of the beamline.

\section{Acknowledgments}

This filter design is based on the design of the Font End Filters at the APS.

We appreciate S. Picologlou's effort in editing this paper.

This work was supported by the U. S. Department of Energy BES Material Science under contract W-31-109-ENG-38.

\section{References}

[1] T. Kuzay. Functional Description of APS Beamline Front Ends, Argonne National Laboratory, ANL/APS/TB-5, 1993.

[2] B. Lay, A. Khounsary, and E. Gluskin. Wiggler A Characteristics and Specifications, Argonne National Laboratory, ANL/APS/TB-11, 1993.

[3] B. Lay, A. Khounsary, R. Savoy, L. Moog, and E. Gluskin. Undulator A Characteristics and Specifications, Argonne National Laboratory, ANU/APS/TB-3, 1993.

[4] R. Laramee. Nozzle Material Properties Manual, Volume VIIIA, Thiocol Corp. - Wasatch Division, for Lockheed Missiles and Space Co., Report No. SE025-A2D-C4-DEV-001, Nov. 1979 
SY

RSYS $=S O L U$

$\mathrm{DMX}=.004263$

SMN $=-26.703$

SMNB $=-33.716$

$S M X=10.912$

$. S M X B=25.681$

$\quad-26.409$

$-24.352$

$-22.295$

$-19.944$

$-17.887$

$-15.536$

$-13.479$

$-11.128$

$-9.071$

$-6.72$

$-4.663$

$-2.312$

$-.254834$

2.096

4.153

6.504

8.561

10.912

Figure 6

APS wiggler beam

on $300 \mu \mathrm{m} \mathrm{C}$

Stress in $\mathrm{MPa}$

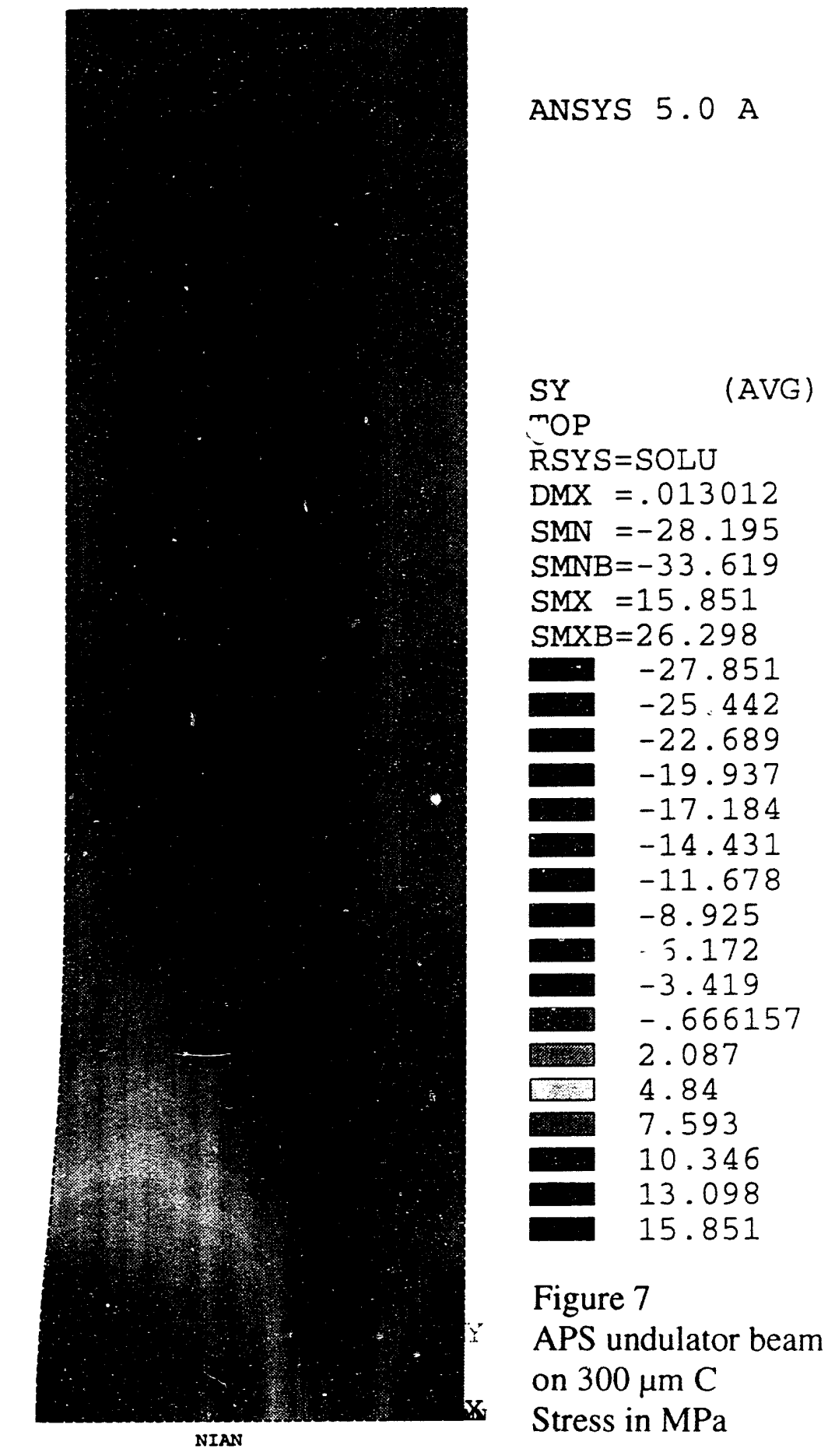

Figure 7

APS undulator beam on $300 \mu \mathrm{m} \mathrm{C}$

Stress in $\mathrm{MPa}$ 


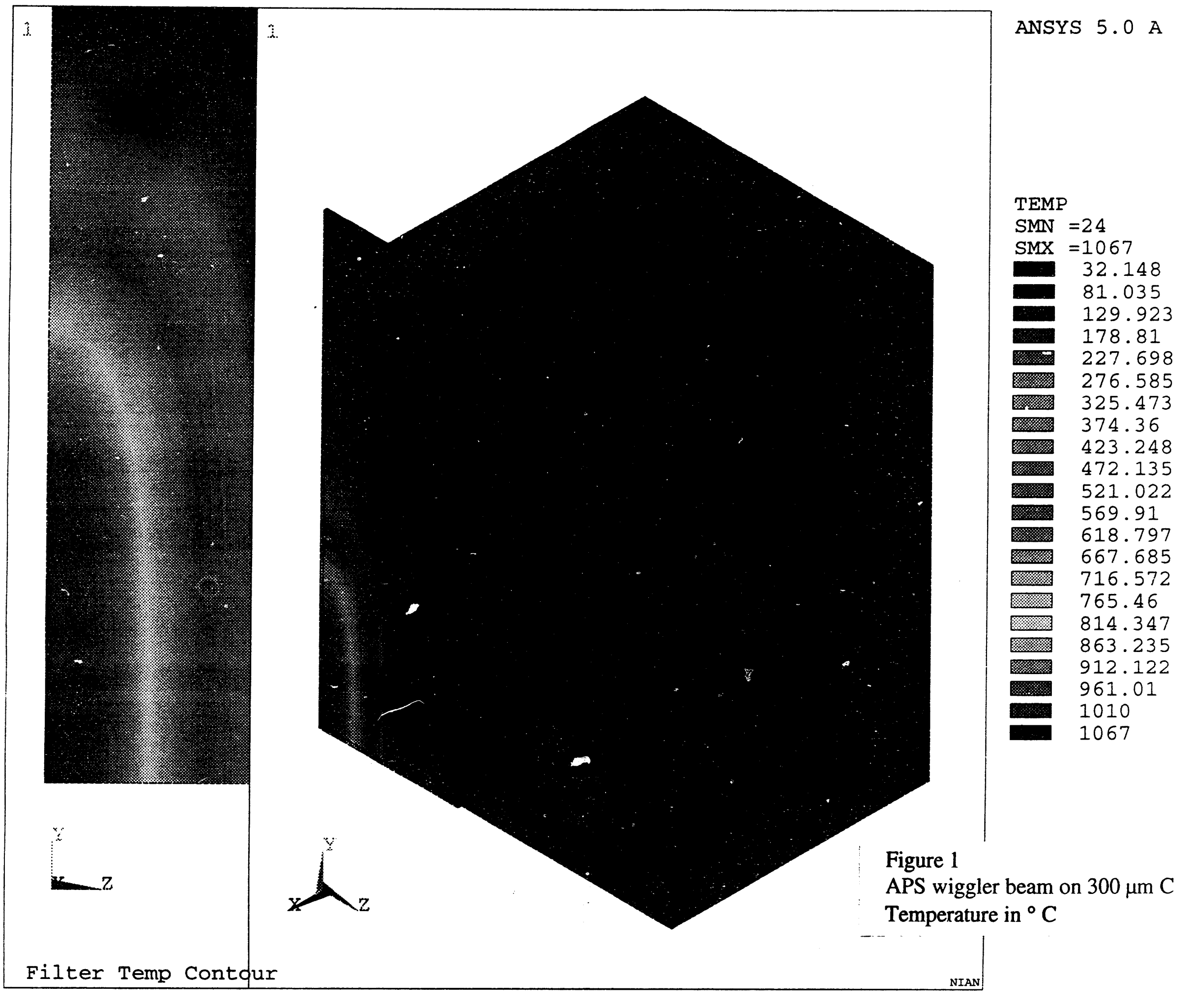




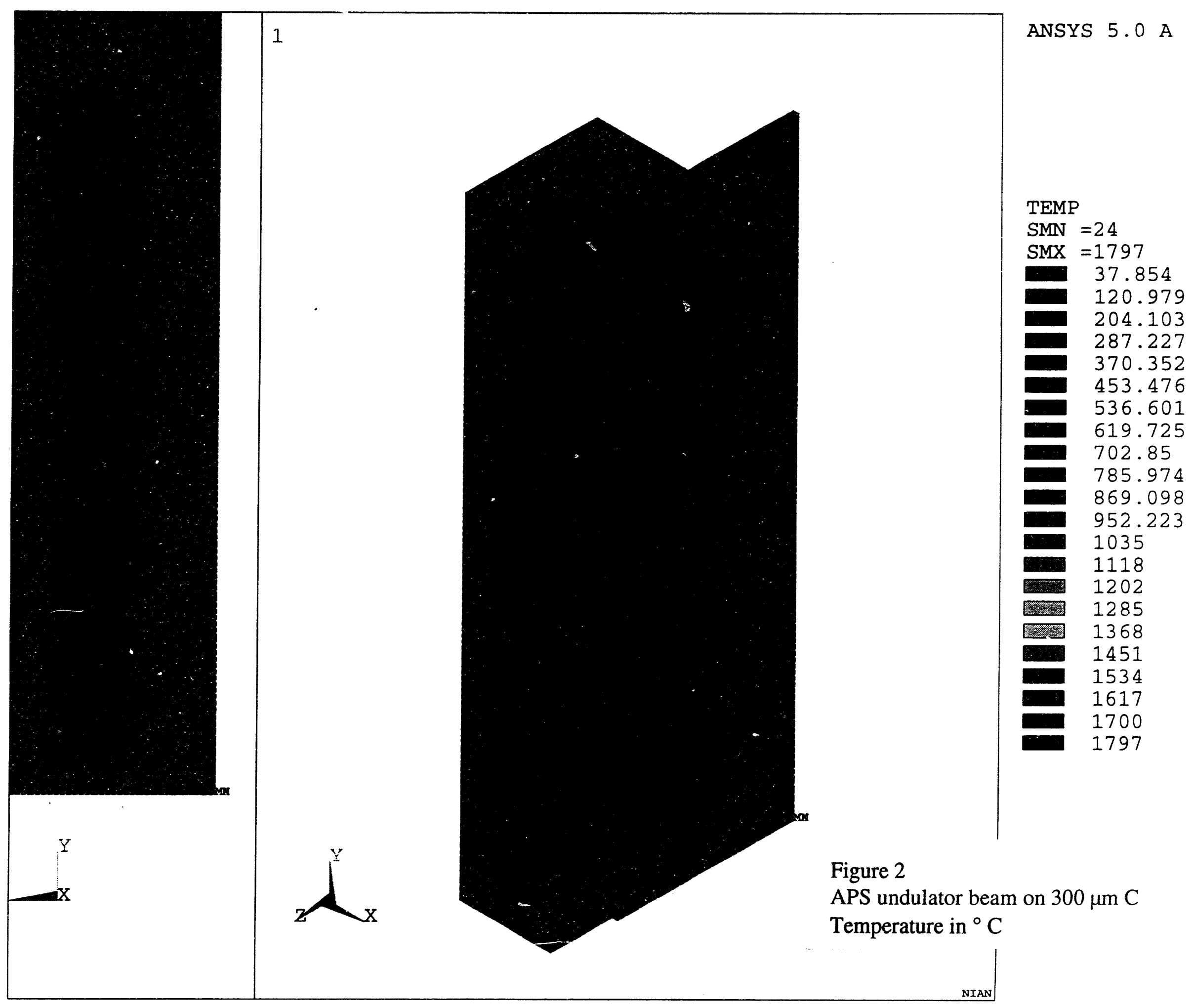



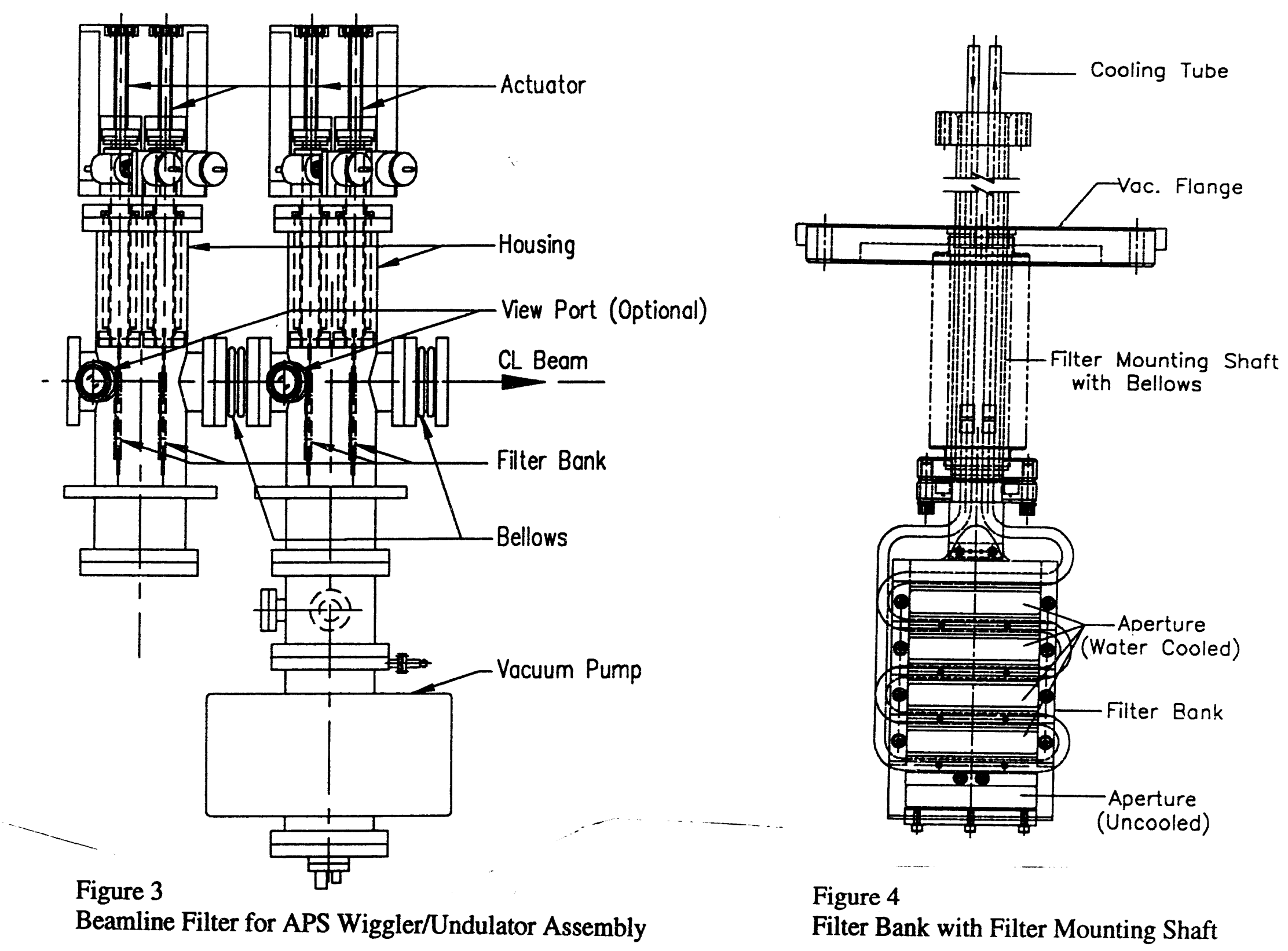

Figure 4

Filter Bank with Filter Mounting Shaft 


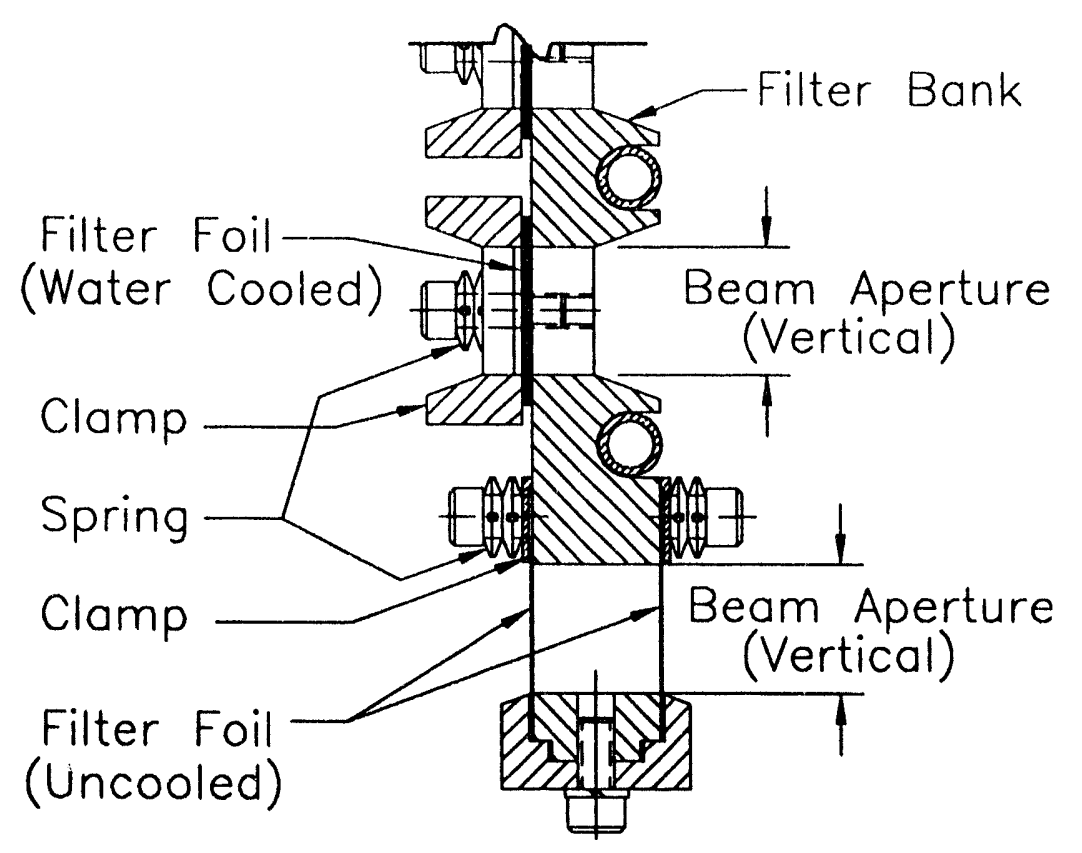

Figure 5

Clamping Assembly

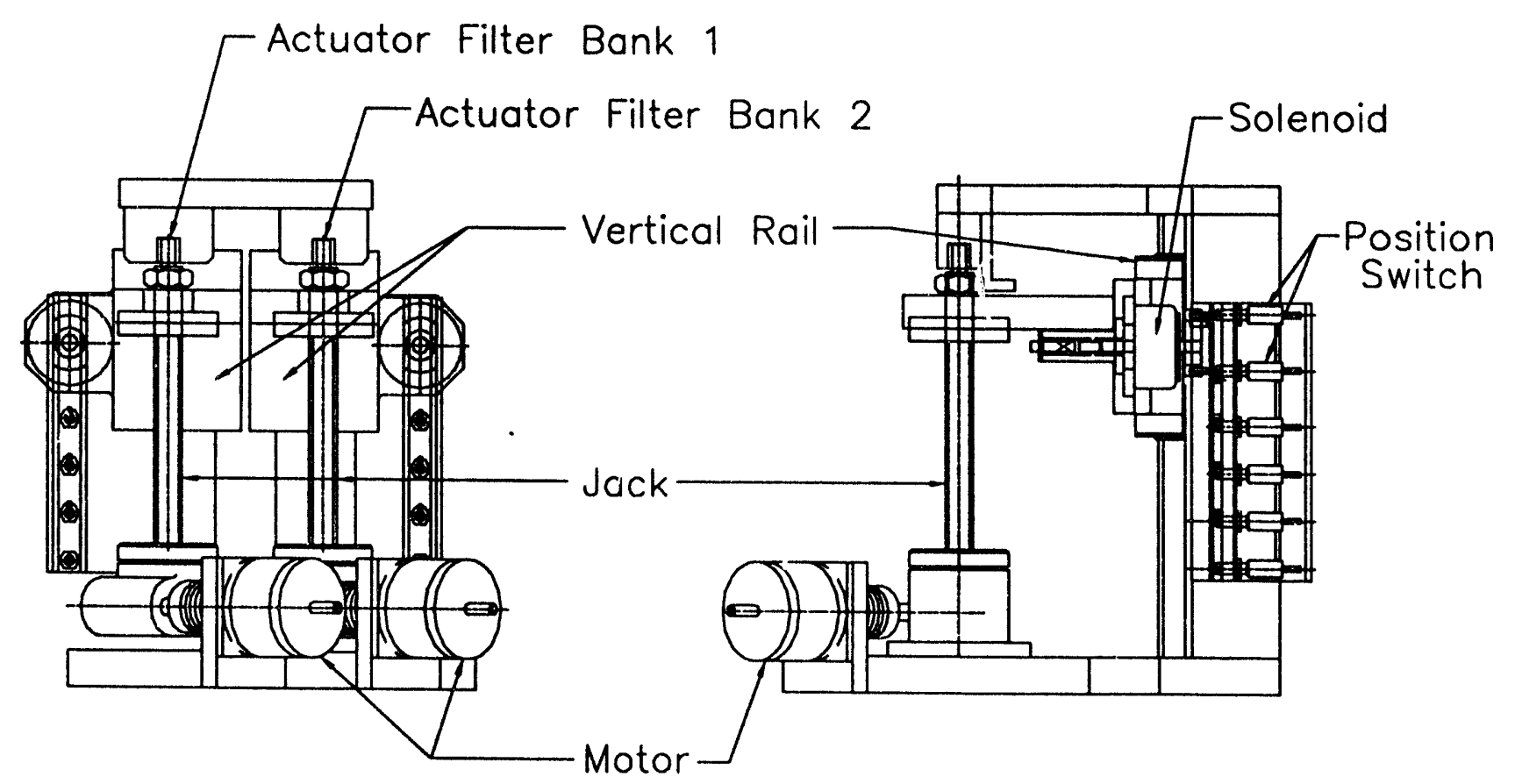

Figure 8

Filter Actuator 

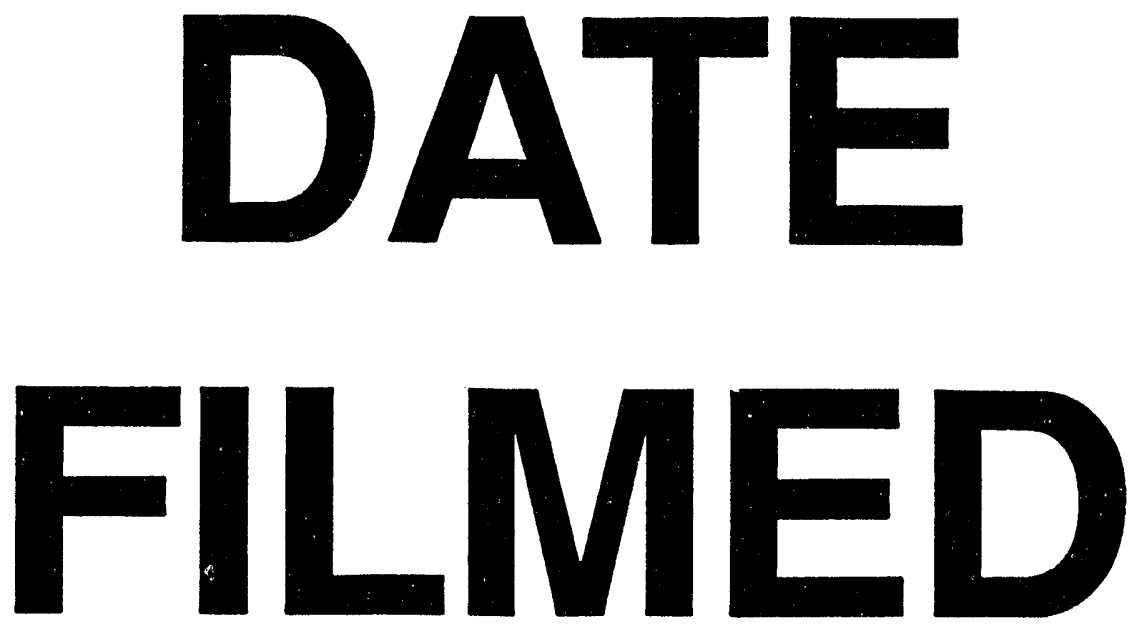

$10 / / 9 / 94$
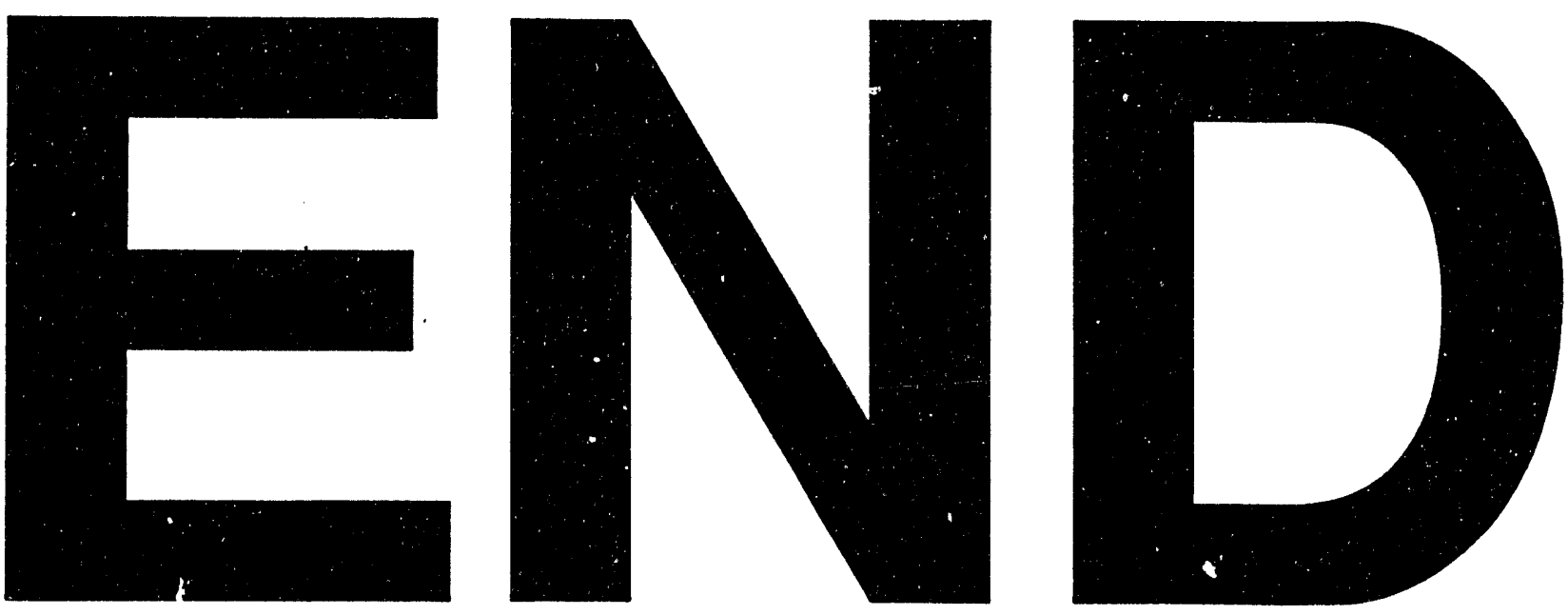
